\title{
FORMAÇÃO INICIAL DE PROFESSORES DE CIÊNCIAS NA AUSTRÁLIA, BRASIL E CANADÁ: UMA ANÁLISE EXPLORATÓRIA
}

\author{
Science teacher preparation in Australia, Brazil, \\ and Canada: an exploratory analysis
}

\author{
Paulo Sérgio Garcia ${ }^{1}$ \\ Xavier Fazio ${ }^{2}$ \\ Debra Panizzon ${ }^{3}$
}

\begin{abstract}
Resumo: A principal justificativa para estudos comparativos em Educação é a promoção de um entendimento regional, local, por meio de análises e cooperação internacional. Na área do ensino de ciências, existem poucas investigações na formação de professores numa perspectiva internacional. Baseado nessa perspectiva, este artigo vem contribuir mostrando uma análise comparativa dos programas de formação de professores de ciências para o Ensino Fundamental em três diferentes contextos: Austrália, Brasil e Canadá. Apresenta-se uma análise qualitativa das similaridades e diferenças por meio da comparação da política de certificação de professores de ciências e das exigências das instituições formadoras numa específica jurisdição de cada país. Por meio dessa análise, identifica-se um número coerente de similaridades, destacando-se os mecanismos de funcionamento e as estruturas comuns que dão suporte aos programas de formação nas três realidades estudadas. Os resultados apresentados são importantes para futuros estudos comparativos na formação de professores de ciências.
\end{abstract}

Palavras-chave: Ensino de ciências. Formação de professores. Estudos comparativos.

\begin{abstract}
The overarching rationale for comparative studies research in education is to promote local understanding through international analysis and cooperation. In the area of science teacher education, there is only one significant and recent publication that addresses science teacher education from an international perspective. This paper builds upon this seminal work and fills a void in science educational research by reporting on a comparative analysis of elementary science teacher preparation programs across three different contexts: Australia, Brazil, and Canada. Specifically, the research focus was to provide a qualitative analysis of the similarities and differences through a comparison of science teacher certification policy and general institutional program requirements of a specific jurisdiction within each nation. Emerging from these analyses were a number of coherent similarities, highlighting common structural and functional mechanisms underpinning teacher education preparation. The findings from this study bode well for future comparative studies research of science teacher education.
\end{abstract}

Keywords: Science education. Teacher education. Comparative studies.

\footnotetext{
${ }^{1}$ Licenciatura em Pedagogia, doutorando em Educação. Membro pesquisador do grupo de pesquisa "Ensino de Ciências e Educação a Distância” (FEUSP). São Paulo, SP, Brasil. <garciaps@usp.br>

${ }^{2}$ Licenciatura em Biologia, phd em Science Education. Associate Professor, Faculty of Education, Brock University. Ontario, Canadá. <xavier.fazio@brocku.ca>

${ }^{3}$ Licenciatura em Biologia, phd Science Education. Deputy Director, Flinders Centre for Science Education in the $21^{\text {st }}$ Century, Flinders University. New South Wales, Australia. < debra.panizzon@flinders.edu.au>
}

${ }^{1}$ Rua Monte Alegre, 199, apto. 12

São Caetano do Sul, SP

$09.531-110$ 


\section{Introdução}

Reconhecendo as diferenças políticas, culturais e históricas de cada país, muitas vezes não é tarefa simples justificar o que de fato pode ser aprendido e compartilhado por meio de estudos comparativos em Educação. No entanto, recentemente, Phillips (2000) definiu as razões para a realização de estudos comparativos na área de Educação, incluindo, dentre outros fatores:

- A descoberta de possíveis alternativas para a organização do sistema educacional;

- As descrições de quais poderiam ser as consequências de determinadas reformas, avaliando-se experiências similares em vários países;

- A possibilidade de se fomentar a cooperação e o entendimento mútuo entre as nações, discutindo-se, política e culturalmente, as similaridades e diferenças, e buscando explicações para elas.

$\mathrm{Na}$ área de formação de professores de ciências, uma das poucas recentes publicações na perspectiva internacional é a de Abell (2000), que editou a publicação Science teacher education: an international perspective. Os autores investigaram de forma comparativa, em vários contextos culturais: as políticas, as questões práticas da formação de professores de ciências, bem como a aprendizagem na formação inicial. No entanto, ainda existe uma carência de estudos comparativos sobre esse tema, embora algumas exceções existam (COBB, 1999). Além disso, nos periódicos de pesquisa em Educação científica, existem poucos estudos comparativos sobre a formação de professores de ciências ou sobre aqueles que são candidatos à docência (LLOYD et al., 1998).

Este estudo, tendo em vista a relevância deste tipo de comparação internacional na formação de professores, mostra uma análise comparativa da formação de professores de ciências para o Ensino Fundamental entre três contextos diferentes: Austrália, Brasil e Canadá, cobrindo um vazio nesse tipo de pesquisa. Inicialmente, o estudo descreve os contextos educacionais de cada país, a fim de promover uma visão ampla sobre as atuais políticas e práticas educacionais. Em seguida, retrata, comparativamente, a formação de professores para o Ensino Fundamental, focando um contexto específico (exemplo: estado, município) dentro de cada nação. Por fim, realiza uma análise comparativa sobre a formação nessa área, mostrando as similaridades e diferenças em cada realidade estudada.

\section{Contextos educacionais}

\section{Austrália}

$\mathrm{Na}$ Austrália, a responsabilidade pela Educação está dividida entre os seis Estados e dois Territórios, o que resulta em oito órgãos (Departamentos) educacionais diferentes que monitoram a grade curricular, as avaliações e as normas educacionais em todo o país. Não há, portanto, um único departamento cuidando de toda a Educação do país.

Esta forma de administração descentralizada, que permite que cada jurisdição atenda às necessidades dos alunos organizando grades curriculares compatíveis com o contexto educacional específico (REID, 2005), converteu-se, durante muitos anos, em oito currículos dife- 
rentes em vigor no país. Embora apoiada por muitos educadores, esta proposta propicia falta de consistência em nível nacional. Para enfrentar esta questão, mudanças no sentido de implementar uma Grade Curricular Nacional estão sendo discutidas em meio a grandes debates e controvérsias. Neste ínterim, o governo federal instituiu o National Statements of Learning (Padrões Nacionais de Aprendizagem) em cinco disciplinas, incluindo Ciências (AUSTRALIA, 2006).

Os padrões referentes a Ciências compreendem três áreas amplas: Ciência como Empenho/Esforço Humano, Ciência como uma forma para aprender, e Ciência como Corpo do Conhecimento. No momento, estes padrões estão orientando o desenvolvimento dos currículos em cada Estado e/ou Território.

A formação de professores de Ciências para o Ensino Fundamental é credenciada no New South Wales (NSW) Institute of Teachers, e isso requer que as Universidades sejam responsáveis por seus programas e garantam a qualidade dos mesmos.

\section{Brasil}

No Brasil, o Ministério da Educação (MEC) é o instituto responsável por organizar e integrar as políticas de Educação em nível nacional. Por intermédio de suas Secretarias, coordena as diretrizes políticas de organização, avaliação e formação de professores relacionadas com a Educação Básica e com o Ensino Superior (Universidades e Institutos de Educação). No entanto, os estados e os municípios também lançam suas diretrizes e indicações para seus sistemas de Educação (com base nas políticas do MEC), o que acentua algumas diferenças, dentre outras, no currículo, na avaliação e no controle.

A disciplina Ciências, tradicionalmente, é lecionada nos anos finais do Ensino Fundamental (EFII). Os conteúdos da disciplina estão definidos nas Diretrizes Curriculares Nacionais para o Ensino Fundamental (DCN-EF), e incluem um conjunto multidisciplinar que engloba conteúdos de Biologia, Física, Geologia, Astronomia e Química (GARCIA et al., 2006). O ensino de Ciências baseia-se, ainda, em quatro grandes eixos temáticos: Terra e Universo, Vida e Ambiente, Ser Humano e Saúde, Tecnologia e Sociedade. Além disso, com o intuito de trabalhar cidadania com os estudantes, os Parâmetros Curriculares Nacionais preveem os chamados Temas Transversais, que incluem: Ética, Pluralidade Cultural, Meio Ambiente, Saúde, Orientação Sexual e Trabalho e Consumo (BRASIL, 1998a; 1998b). Apesar dessas diretrizes, não há um currículo único em todos os estados e municípios.

De acordo com a última Lei de Diretrizes e Bases da Educação Nacional (LDB), de 1996, apenas duas instituições estão habilitadas para promoverem a formação dos profissionais da Educação Básica no Brasil: as Universidades e os Institutos Superiores de Educação (art. 62). A certificação de professores para atuação nas séries finais do Ensino Fundamental, que tem validade em todo o território nacional, é, portanto, uma atividade regulada pelo Governo, e somente instituições autorizadas podem credenciar os professores à docência.

A formação dos professores de Ciências para as séries finais do Ensino Fundamental está regulamentada pelas Diretrizes Curriculares Nacionais para a Formação de Professores da Educação Básica, em nível superior, curso de licenciatura, de graduação plena (resolução CNE/CP 1/2002 e parecer CNE/CP 009/2001), e, também, pelas Diretrizes Curriculares para os cursos de Ciências Biológicas (parecer CNE/CES 1301/2001 e resolução CNE/CES 
Garcia, P. S.; Fazio, X.; Panizzon, D.

7/2002). Os currículos de formação de professores, respeitando-se as diretrizes citadas, são de responsabilidade das instituições formadoras.

No Brasil, apesar dos avanços significativos trazidos pela última LDB, que acabou, por exemplo, com os cursos de curta duração (Licenciatura Curta), não há uma legislação específica para a formação de professores de ciências para o EFII. Isso não favorece a construção de uma identidade própria para a formação desses profissionais. Resulta que, sem esta especificidade, a maioria dos professores que leciona neste nível continua a ser formada em cursos de Biologia (Licenciatura Plena), o que, de acordo com alguns autores, não é adequado para essas séries, pois não é apropriado ensinar ciências para os estudantes do EFII focando, exclusivamente, fatos biológicos (ARGÜELO; GIMENES, 1991; KRASILCHIK, 2004). No entanto, existem alguns poucos cursos voltados para a formação do profissional para ministrar aulas no EFII, dentre eles o curso de licenciatura em Ciências Naturais da Universidade de São Paulo (campus USP Leste), que será objeto de estudo de caso na presente pesquisa.

Segundo Magalhães Jr. e Oliveira (2005), a formação de professores para esse nível de ensino é pouco assumida pelas universidades, e esta falta de identidade constitui um fator negativo para a formação de professores e, consequentemente, para o ensino de ciências, haja vista os resultados dos alunos em exames internacionais como o Programa Internacional de Avaliação Comparada (PISA).

\section{Canadá}

No Canadá, não existe um departamento federal de Educação ou um sistema nacional integrado de Educação (CANADÁ, 2005). Em cada jurisdição, departamentos ou ministérios de Educação são responsáveis pela organização, provisão e avaliação da Educação nos níveis elementar e secundário (idades entre 5-18; da Educação Infantil até a $12^{a}$ série).

As instituições de ensino no sistema pós-secundário (Universidades) apresentam diferentes graus de autonomia em relação ao controle governamental das províncias. Da mesma forma que na Austrália, cada província ou território possui um currículo próprio para o ensino de Ciência e Tecnologia.

Em 1997, o Conselho de Ministros da Educação emitiu o Common Framework for Science Learning Outcomes, K-12: Pan Canadian Protocol for Collaboration on School Curriculum (CANADA, 1997). Esse documento, embora não tivesse força de autoridade em cada uma das jurisdições educacionais do Canadá, foi, de certa forma, adotado por todas as províncias e territórios (FAZIO; BOWERS; MOK, 2007).

No Canadá, a preparação de professores de Ciências é ministrada por instituições credenciadas (Universidades). Cada uma das instituições que oferecem graduação em curso Superior deve submeter-se à legislação educacional de sua província para obter o credenciamento, embora todas possuam controle sobre os próprios currículos para preparação de professores de ciências. 


\section{Metodologia}

A questão central do presente estudo é: quais as semelhanças e diferenças entre os programas de formação de professores de ciências para o Ensino Fundamental de três jurisdições educacionais específicas na Austrália, Brasil e Canadá? Para responder a esta pergunta, foram coletados dados destas jurisdições educacionais a partir da análise de documentos de ministérios e autoridades oficiais de Educação e da documentação de programas universitários de diferentes instituições encontrados em sites e na forma impressa durante os anos de 2007 e 2008.

Os países que participaram desta pesquisa foram selecionados utilizando-se alguns critérios baseados no estudo de Phillips (2000), que conceitualizou os motivos para a prática de estudos comparativos na área de Educação.

Canadá e Austrália foram escolhidos para estudo de caso, pois ambos fazem parte da Commonwealth, que é uma organização internacional com 54 membros independentes. Essas nações cooperam dentro de um quadro de valores e objetivos que foram ratificados na declaração de Singapura. Isso inclui: a promoção da democracia, direitos humanos, liberdade individual, comércio livre, multilateralismo e paz no mundo.

Canadá e Austrália não possuem sistemas federal ou nacional de Educação, resultando na criação, em cada estado ou jurisdição, de um departamento de Educação independente para lidar com o ensino primário e secundário. Em contraste, o Brasil possui um Ministério da Educação Nacional que coordena as diretrizes políticas, currículo e avaliação de todo o país. Assim, embora exista alguma semelhança entre o Canadá e a Austrália, também há diferenças, fornecendo uma comparação interessante com o Brasil, que não tem o mesmo histórico de Educação que os outros dois países.

Os casos estudados no Canadá e na Austrália estão inseridos em estados onde toda a formação, incluindo legislação própria, é voltada para a formação de professores para o Ensino Fundamental, o que não ocorre no Brasil, onde a maioria dos professores que ministram aulas nesse nível de ensino continua sendo formada em cursos de Licenciatura Plena em Biologia ou História Natural (MAGALHÃES JR.; OLIVEIRA, 2005). A formação desses profissionais é realizada em consonância com os objetivos, currículo, metodologias relacionadas ao Ensino Médio.

A escolha do caso no Brasil, o curso de licenciatura em Ciências Naturais da Universidade de São Paulo (USP-Leste), foi proposital, pois o curso é um dos poucos que existe (quatro em todo o país) voltado exclusivamente para a formação de professores mais generalistas para a atuação no Ensino Fundamental (MAGALHÃES JR.; OLIVEIRA, 2005), como acontece nos outros dois países. Krasilchik (2004) afirma que, considerando como base a característica generalista da disciplina Ciências físicas e biológicas, é preciso discutir e construir cursos em que os currículos sejam, particularmente, desenhados para a docência das Ciências em nível Fundamental. Este estudo pretende fornecer alguns elementos para esta discussão.

Phillips (2000) afirma que a análise de experiências similares em vários países e a busca de explicações para elas possibilita a compreensão de possíveis alternativas para a organização dos sistemas de ensino. Essa compreensão é relevante, pois, como citam Magalhães Jr. e Oliveira (2005), poucas Universidades em nosso país assumiram a formação de professores para o Ensino Fundamental, que contínua sem identidade própria, gerando consequências 
negativas para a formação e para o ensino de Ciências. No entanto, cabe lembrar que a apreciação de experiências similares em outros contextos não sugere a reprodução das mesmas.

As informações coletadas neste estudo incluíram dados referentes a contextos jurisdicionais e nacionais, bem como políticas e programas de certificação de professores de ciências para o Ensino Fundamental. A análise dos dados de forma qualitativa envolveu a abordagem da teoria fundamentada (CRESWELL, 2002; STRAUSS; CORBIN, 1990). Este enfoque refere-se à teoria que é indutivamente desenvolvida a partir de um conjunto de dados. Em nosso caso, o conjunto de dados surgiu de documentação referente aos três países.

A primeira fase desta abordagem traduziu-se pela codificação aberta por meio da segmentação dos dados coletados para permitir a comparabilidade entre as três realidades estudadas. Nesses contextos, foram identificadas as categorias abrangentes por meio da filtragem de dados, usando-se códigos e descritores de maneira constante e reiterativa. Classificamos, então, os códigos em categorias, procurando por similaridades e diferenças entre as jurisdições educacionais de cursos preparatórios para a formação de professores de ciências para o Ensino Fundamental. Finalmente, essas categorias foram reduzidas para permitir a identificação de temas comuns a tais contextos educacionais.

\section{Contexto intrapaíses}

\section{Austrália - estudo de caso de New South Wales}

O credenciamento de todos os cursos/programas de preparação de professores de ciências para o Ensino Fundamental ocorre por meio do NSW Institute of Teachers. O processo exige que as Universidades conduzam uma auditoria de seus programas de estudo para identificar se os professores em treinamento (preservice teachers) atingem os 45 padrões da profissão. O resultado é que, uma vez completado o curso, considera-se que o aluno atingiu a condição de "Graduate Teacher" e está apto a lecionar em escolas de New South Wales. É importante ressaltar que estes padrões compreendem sete aspectos:

. Os professores conhecem o conteúdo da matéria e sabem como ensinar este conteúdo aos seus alunos;

. Os professores conhecem seus alunos e a forma como aprendem; do efetivo;

. Os professores planejam, avaliam e preparam relatórios com vistas a um aprendiza-

. Os professores comunicam-se efetivamente com seus alunos;

- Os professores criam e mantêm ambientes de aprendizado seguros e desafiadores através de habilidades de gestão da sala de aula;

. Os professores aperfeiçoam continuamente seus conhecimentos e prática profissional; e

. Os professores são membros ativamente engajados em sua profissão e na comunidade em geral (NEW SOUTH WALES INSTITUTE OF TEACHERS, 2005).

Para atingir estes padrões em NSW, espera-se que os professores do Ensino Fundamental demonstrem conhecimentos de Matemática, Inglês, Sociedade e Meio ambiente, Artes, Ciência e Tecnologia. Durante o programa, os alunos completam de um a três cursos em cada 
área (por exemplo, dois de Ciência e Tecnologia, três de Matemática), além de vários cursos envolvendo pedagogia e aprendizagem.

Hoje, há duas formas de entrar em um programa preparatório de professores para o Ensino Fundamental em NSW. A primeira requer que o aluno complete a $12^{a}$ série, o que envolve exames preparados e avaliados externamente para a obtenção do "Higher School Certificate" (ou equivalente). A aceitação no programa (na maioria dos casos) requer que o aluno atinja uma classificação específica, "Tertiary Entrance Score - TER”, que varia a cada ano. Os alunos matriculam-se em um programa de quatro anos de Bacharelado em Educação ministrado em Faculdades de Educação, que abordam as disciplinas relacionadas, pedagogia e grades curriculares. $\mathrm{Na}$ segunda opção, o aluno, através de um curso de três anos, obtém o diploma de Bacharel em Artes/Estudos Gerais/Ciências (ou outro diploma universitário similar), seguido de um programa de Educação de um ou dois anos (Bacharel em Ensino Elementar) em uma Faculdade de Educação (INGVARSON et al., 2006)

Com relação à Ciência e Tecnologia, ambos os caminhos (currículos) admitem professores em formação com pouca experiência científica. Esta formação é realizada por meio de cursos que se destinam a dar conta da aquisição de conhecimentos em Ciência e Tecnologia, necessários para ensinar alunos do Ensino Fundamental.

O construtivismo e a importância da construção do conhecimento a partir de experiências e entendimentos pessoais (DRIVER et al., 1994; HAND; TREAGUST; VANCE, 1997) dão sustentação às unidades de Ciência e Tecnologia nos programas de preparação de professores em NSW. Em cada curso de Ciência e Tecnologia, são desenvolvidos conceitos científicos, proporcionando aos professores em formação experiências inéditas a partir de situações práticas. Apesar de algumas aulas expositivas, a maior parte do processo de ensino é conduzida por meio de oficinas sobre temas científicos específicos. Esses temas são construídos em torno das seis linhas de conteúdo que fazem parte do planejamento de ensino de Ciência e Tecnologia de NSW, incluindo: "ambientes construídos", "informação e comunicação", "seres vivos", "fenômenos físicos", "produtos e serviços" e a "terra e seus arredores".

Um enfoque central das oficinas é a abordagem investigativa por intermédio de grupos de trabalho e colaboração. As oficinas destinam-se, dentre outras coisas, a levar os professores em formação ao desenvolvimento de habilidades de observação, questionamento, previsão, teste, coleta, registro e análise de dados (NEW SOUTH WALES, 2006), e, ao mesmo tempo, fazê-los ampliar a compreensão dos conceitos científicos. Desse modo, desenvolvem conhecimentos e habilidades associados a um elenco de estratégias pedagógicas adequadas à sala de aula do Ensino Fundamental. É uma prática comum que os professores em treinamento sejam avaliados de forma contínua, por meio de diferentes métodos (por exemplo, portfolios, auditorias de trabalho de campo). Entretanto, uma incidência crescente de plágios, nos trabalhos apresentados pelos futuros professores, levou a maioria das Universidades a incluírem exames cujos resultados compõem até $30 \%$ da nota final.

Ao mesmo tempo em que a contribuição dos professores da Universidade ao programa de formação do professor é essencial, é pré-requisito que todos os professores em formação para o Ensino Fundamental cumpram um número específico de dias estagiando em escolas. Até o momento, são exigidos cento e dez dias para os alunos do curso de Bacharel em Educação (ou seja, para o curso de quatro anos nas Faculdades de Educação) e sessenta dias para os cursos de Bacharel em Estudos Gerais/Bacharel em Educação Elementar. Claramen- 
te, esta diferença destaca uma questão com relação à desigualdade na experiência prática exigida dos dois grupos de alunos.

Ao considerar a formação do professor de Ciências para o Ensino Fundamental no contexto de NSW, percebe-se que há muito espaço para que docentes engajem seus alunos usando técnicas de solução de problemas e/ou processos investigativos. $\mathrm{O}$ atual plano de ensino viabiliza este aspecto fornecendo várias áreas de conteúdo com determinação mínima sobre como e em que medida estas áreas devem ser contempladas, juntamente com as oportunidades de se desenvolverem habilidades baseadas em investigação. No entanto, como para a maioria dos alunos que entra em cursos de formação de professores falta confiança nos conhecimentos adquiridos e experiência no ensino (DILLON et al., 2000; GOODRUM; COUSINS; KINNEAR, 1992), muitos deles se sentem rapidamente intimidados e paralisados. Com isso, o ciclo de distanciamento da Ciência, que é tão comum na literatura (GOODRUM; HACKLING; RENNIE, 2001), é reforçado, porque os docentes continuam dando suas aulas apoiados em folhas de instruções e atividades dirigidas, e isso faz com que os alunos se sintam cada vez mais desinteressados. Atualmente, NSW está desenvolvendo um novo plano de ensino para contemplar algumas destas questões.

\section{Brasil}

No Brasil, a formação de professores de ciências para o EFII é realizada na mesma sintonia curricular e especificidade de objetivos da formação para o Ensino Médio; ou seja, há pouca distinção filosófica e metodológica entre os dois tipos de formação. Desta forma, a quase totalidade dos profissionais que atuam no Ensino Fundamental é formada em programas que estão centralizados na área de ciências biológicas: Licenciatura Plena em Biologia ou História Natural (MAGALHÃES JR.; OLIVEIRA, 2005).

Esta formação de professores foi regulamentada, de forma mais global, pela Lei de Diretrizes e Bases da Educação Nacional - Lei 9.394/96 (BRASIL, 1996), em especial o art. $3^{\circ}$, inciso VII, arts. $9^{\circ}, 13,43,61,62,64,65$ e 67, e pelo Plano Nacional de Educação - Lei 10.172/2001 (PLANO..., 2001), item IV, que trata do magistério na Educação Básica e define todas as diretrizes e objetivos da formação inicial para a docência na Educação Básica.

De forma mais específica, esta formação foi estabelecida pelo Parecer CNE/CP 9/ 2001 (BRASIL, 2002a), que define as Diretrizes Curriculares Nacionais para a formação de professores da Educação Básica, em nível Superior, nos cursos de licenciatura de graduação plena; pelo Parecer CNE/CP 27/2001 (BRASIL, 2002b), que dá nova redação ao item 3.6, alínea c, do Parecer CNE/CP no 9/2001; pelo Parecer CNE/CP 28/2001 (BRASIL, 2002c), que dá nova redação para o Parecer CNE/CP 21/2001, estabelecendo a duração e carga horária; pela Resolução CNE/CP 1/2002 (BRASIL, 2002b), que institui as Diretrizes Curriculares Nacionais para a formação de professores da Educação Básica, em nível Superior, cursos de licenciatura, de graduação plena; e pela Resolução CNE/CP 2/2002 (BRASIL, 2002c), que, atualmente, institui a duração e a carga horária.

No campo ainda mais específico da formação de professores de Ciências, a regulamentação está atrelada às Diretrizes Curriculares Nacionais para os Cursos de Ciências Biológicas instituída pelo Parecer CNE/CES 1.301/2001 (BRASIL, 2001) e confirmada pela Resolução CNE/CES 7, de 11/03/2002 (BRASIL, 2002a), que destaca os conteúdos curriculares 
básicos para ambas as habilitações, bem como as características específicas para a Licenciatura e para o Bacharelado.

Grosso modo, o perfil do futuro professor deverá, dentre outras coisas, ser o de um profissional crítico, com bom conhecimento teórico da diversidade dos seres vivos, responsável pela conservação do meio ambiente e consciente de sua função de educador.

O currículo da formação de professores é baseado em competências e habilidades, pautado, dentre outras coisas: na pesquisa, na atuação multidisciplinar, na responsabilidade, nas relações entre a Ciência, Tecnologia e sociedade, na cidadania etc., conforme o parecer CNE/CES n 1.301/2001 (BRASIL, 2001).

A estrutura curricular contempla, dentre outros princípios: formação básica inter e multidisciplinar; atividades de campo e de laboratório; equilíbrio entre a aquisição de conhecimentos, habilidades, atitudes e valores; ensino problematizado e contextualizado; a construção de competências; atividades curriculares e extracurriculares de formação, como, por exemplo, iniciação científica, estágios etc., de acordo com o parecer CNE/CES n 1.301/2001 (BRASIL, 2001). O currículo pode ter formato modular, de forma seriada, anual, ou semestral. Os conteúdos básicos englobam os conhecimentos da Biologia e das áreas das ciências exatas, da terra e humanas etc. São conteúdos básicos: biologia celular, molecular e evolução, diversidade biológica, ecologia, fundamentos das ciências exatas e da terra, fundamentos filosóficos e sociais. Alguns conteúdos específicos também devem ser contemplados nas áreas de Química, Física e da Saúde. A formação pedagógica, voltada para a preparação tanto para o ensino de Ciências no nível Fundamental como para o ensino da Biologia no nível Médio, deverá propiciar, ao futuro professor, suas especificidades e uma visão geral da Educação e dos processos formativos dos alunos (BRASIL, 2001).

A carga horária do curso é de, no mínimo, duas mil e oitocentas horas: com quatrocentas horas de prática como componente curricular, vivenciadas ao longo do curso; quatrocentas horas de estágio, mil e oitocentas horas de aulas para os conteúdos curriculares de natureza científico-cultural e duzentas horas para outras formas de atividades acadêmicocientífico-culturais, de acordo com a resolução CNE/CP 2/2002 (BRASIL, 2002c).

Este modelo de formação de professores está formando a grande maioria dos professores de ciências que estão atuando no Ensino Fundamental, no entanto já existem, de acordo com Magalhães Jr. e Oliveira, (2005), três cursos no estado do Paraná e um, em São Paulo, voltados para atender as exigências de uma formação mais generalista para o Ensino Fundamental. Neste estudo o curso de Licenciatura em Ciências Naturais da USP Leste será utilizado como estudo de caso e servirá de base para análise em relação às outras duas realidades estudadas.

\section{Estudo de caso de São Paulo: curso de Ciências Naturais da USP}

No Brasil, não há uma legislação específica para a certificação de professores do Ensino Fundamental. Isso faz com que a maioria dos professores que desejam lecionar nesse nível procure cursos de licenciatura em Biologia. Uma das poucas experiências de formação de professores propriamente ligada a esse nível de ensino é a da USP Leste, que oferece um curso de Licenciatura Plena em Ciências Naturais.

O curso está voltado para o estudo das Ciências da Natureza, utilizando conhecimentos da Física, da Química, das ciências da vida e da terra, de forma integrada. Os saberes do 
funcionamento da natureza como um todo, da história natural da terra e do universo são enfatizados na formação. Esse conjunto de conhecimentos integrados de todas as Ciências da Natureza (Ciências da terra, da vida, Astronomia, Física e Química) torna-se fundamental quando se pensa na construção de uma nova relação do ser humano com a natureza, e na formação de cidadãos críticos e responsáveis em relação ao planeta.

Pode-se destacar, como inovação deste programa, o rompimento com a organização departamental, obrigatória pela Lei n. 5.540/68 (BRASIL, 1968), embora se mantenha ainda a divisão das disciplinas por semestre ligada a créditos.

O curso tem a duração total de oito semestres, ou seja, quatro anos. A carga horária total é de 3350h, assim distribuídas: 2415h (161 créditos-aula em disciplinas obrigatórias) mais $120 \mathrm{~h}$ (oito créditos-aula em optativas) correspondentes aos conteúdos curriculares de atividades acadêmico-científico-culturais em sala de aula; $400 \mathrm{~h}$ de prática de ensino vivenciada nas atividades das disciplinas; $400 \mathrm{~h}$ em estágios supervisionados; $210 \mathrm{~h}$ em atividades científico-acadêmico-culturais desenvolvidas com as instituições científicas e culturais da região (FIGUEIREDO NETO, 2003).

Em relação aos critérios para a admissão neste programa de formação de professores, exige-se que o candidato tenha terminado o Ensino Médio e seja ainda aprovado em exame próprio (vestibular) da universidade.

Com o objetivo de formar professores voltados à docência no Ensino Fundamental, o currículo considera não só os saberes específicos em Ciências, mas também a formação pedagógica, que tem, segundo a proposta de curso, estreita relação com as disciplinas específicas e com a realidade local.

O currículo tem uma abordagem interdisciplinar e foi planejado com base em temas e atividades integradas, e não exclusivamente a partir de disciplinas especializadas (como acontece nos cursos de formação de professores em Biologia e áreas afins).

$\mathrm{Na}$ tentativa de relacionar-se com os novos paradigmas da Ciência e da Cultura e as exigências sociais cada vez mais complexas, o primeiro ano do programa funciona como um Ciclo Básico (CB). O ciclo tem o intuito de promover a iniciação acadêmica dos futuros professores por meio de uma abordagem interdisciplinar, bem como de questões abrangentes e fundamentais ao conhecimento científico e social.

O CB tem, como eixo de referência do currículo, atividades de "resolução de problemas", isso com o objetivo de articular as dimensões da teoria e da prática, bem como os conhecimentos científicos e aqueles do cotidiano. Isso visa, dentre outras coisas, fazer com que o futuro professor seja autor e ator das investigações (protagonize) e possa compreender a complexidade dos fenômenos, num processo de troca e cooperação entre docentes, estudantes e comunidade (FIGUEIREDO NETO, 2003).

Já desde o primeiro ano da Licenciatura em Ciências da Natureza, o aluno estabelece contato com as disciplinas pedagógicas, como é sugerido pelo Programa de Formação de Professores da USP (CARVALHO, 2004).

De acordo com Figueiredo Neto (2003, p. 10):

A partir do segundo ano, o curso desenvolve-se com a formação pedagógica geral e específica em Ciências da Natureza (Física, Química, Ciências da Terra, do Universo e da Vida e os conteúdos necessários 
em Matemática e Ciências da Informação). Os conteúdos pedagógicos e de Ciências da Natureza são tratados paralelamente ao longo de todos os semestres, permitindo que as disciplinas pedagógicas estejam presentes em todo o curso de Graduação desde o seu início, fazendo com que o licenciando possa refletir constantemente sobre a questão da Educação, evitando assim o apêndice das disciplinas pedagógicas isoladas desconectadas dos conteúdos de conhecimento específico. Além disso, permite que o aluno exerça atividades pedagógicas específicas de forma progressiva, à medida que vão aumentando seus conhecimentos específicos, durante os diversos estágios e atividades práticas.

Pode-se dizer que a proposta visa superar a desarticulação entre a teoria e a prática e entre a Universidade e as escolas, presente hoje nos cursos de formação de professores.

Destaca-se, na proposta pedagógica, a integração dos conteúdos das disciplinas com as atividades de estágio e de laboratório realizadas durante o curso. Esse caráter integrador do currículo articula os conteúdos de Matemática, Ciências físicas e biológicas, Sociedade, Meio ambiente e Cidadania, Arte, Literatura e Cultura, Ciência e Tecnologia. A proposta também é norteada pelo uso dos novos recursos de multimídia e as ferramentas informáticas, ou seja, as novas tecnologias de informação e comunicação (NTICs).

Além dos estudos previstos no currículo e vividos na Universidade com os docentes, o futuro professor tem de realizar estudos de estágios em escolas públicas (duzentas e cinquenta horas) e mais cento e cinquenta horas em escolas privadas, museus ou feiras de ciências. $\mathrm{O}$ total é de quatrocentas horas, distribuídas da seguinte forma: cento e vinte horas associadas à disciplina Didática das Ciências Naturais; cento e vinte horas associadas à disciplina Metodologia de Ensino em Ciências da Natureza I; cem horas associadas à disciplina Metodologia de Ensino em Ciências da Natureza II e sessenta horas associadas à disciplina Educação Ambiental (Art. $n^{\circ} 1$ e 2 do Regimento dos estágios curriculares supervisionados do Curso de Licenciatura em Ciências da Natureza - EACH-USP) (UNIVERSIDADE DE SÃO PAULO, 2007).

O diploma de licenciatura em Ciências da Natureza é concedido pelo programa de formação de professores da Universidade de São Paulo.

Já existem, por um lado, estudos realizados criticando alguns mecanismos que dão sustentação filosófica e metodológica (questão da interdisciplinaridade e da resolução de problemas) deste tipo de formação (SANTOS; INFANTE-MALACHIAS, 2008). No entanto, é preciso, claramente, a criação de estudos mais sistemáticos para se compreender mais sobre os impactos desse tipo de formação de professores de Ciências. Por outro, tendo em vista o embasamento da proposta é, pelo menos, possível refletir mais profundamente sobre uma formação mais generalista na preparação de professores para o Ensino Fundamental, o que há muito já é defendido por alguns acadêmicos na área de Ciências.

\section{Canadá - estudo de caso de Ontário}

Todos os programas de formação inicial de professores em Ontário, sob os auspícios de Universidades, são credenciados por uma organização reguladora denominada "Ontario College of Teachers - OCT". A revisão de programas de formação de professores inclui 
determinar se eles refletem a grade curricular atual de Ontário, além da legislação e política governamental do Ministério da Educação de Ontário, incluindo os Standards of Practice for the Teaching Profession (Padrões de práticas para o ensino da profissão) and the Ethical Standards for the Teaching Profession (Padrões éticos para o ensino da profissão) do OCT (CANADA, 2008). Está incluída, também, uma revisão da estrutura conceitual, conteúdo do curso, formato e estrutura do programa, exigências de prática e materiais de aprendizagem, recursos disponíveis para os candidatos a professor e avaliação do conhecimento adquirido, qualificações da faculdade, políticas institucionais e procedimentos que regem o programa.

Ao mesmo tempo em que os padrões do OCT para certificação de programas de formação inicial de professores em Ontário são abrangentes, não existem critérios específicos destacados para cada matéria (além da coerência da grade curricular) para esta certificação. Além disso, os programas de formação de professores são certificados como um todo, e não como programas individuais baseados em cada matéria.

Em Ontário, há dois caminhos para que uma pessoa se torne um professor qualificado para lecionar no Ensino Fundamental: (a) bacharelado de um ano ou um curso profissionalizante consecutivo de um ano; (b) um programa simultâneo ou integrado de quatro ou cinco anos (EPP; EPP, 2000). Ao final de cada programa, o diploma de Bacharel em Educação (B.Ed.) é concedido pelo programa de formação de professores. No entanto, pelo caminho simultâneo, outro diploma de curso Superior pode ser obtido (por exemplo, Bacharel em Artes, Bacharel em Ciências), uma vez que os cursos são, em geral, concluídos simultaneamente. $\mathrm{Na}$ maioria das universidades de Ontário, mesmo os alunos que cursam programas simultâneos vindos diretamente do curso secundário, no final, irão se encontrar nas mesmas salas de aulas dos alunos matriculados em cursos consecutivos (EPP; EPP, 2000).

O diploma de magistério obtido a partir destas duas trajetórias refere-se a duas sequências de classificação: "primary/junior" (séries de 1ª a $6^{\text {a }}$; idades de seis a 11 anos) e "junior/ intermediate" (séries de $4^{\mathrm{a}}$ a $10^{\mathrm{a}}$; idades de oito a 15 anos). Note-se que a maioria das escolas de Ensino Fundamental em Ontário inclui as séries de $1^{\mathrm{a}}$ a $8^{\mathrm{a}}$. Além disso, a grade curricular para o Ensino Fundamental de Ciência e Tecnologia (CANADA, 2007) abrange apenas da $1^{a}$ a $8^{a}$ série. Portanto, os professores do Ensino Fundamental, geralmente, não lecionam em escolas secundárias, mesmo que, como professores dos níveis "junior/intermediate" sejam habilitados para lecionar para a $9^{\mathrm{a}}$ e $10^{\mathrm{a}}$ série.

Professores dos níveis "primary/junior" não precisam ter uma área de especialidade (por exemplo, Ciências) e são considerados generalistas, capazes de lecionar todas as matérias. Alunos dos programas simultâneos, particularmente os de formação de professores, podem incluir curso ou cursos de Ciências em seu diploma, embora esta não seja uma exigência. Cursos em conteúdos de Ciências tampouco são exigidos para a obtenção do diploma de Bacharel em Educação. Ligeiramente distinto é o caso dos professores dos níveis "junior/intermediate”, que devem ter especialização em uma área de conhecimento (por exemplo, Ciências).

Estes participantes dos cursos para professores do Ensino Fundamental precisam, portanto, ter obtido um diploma superior em Ciências antes de candidatarem-se ao programa inicial de formação de professores, ou devem participar de um curso que seja completado simultaneamente com o programa de magistério.

Os critérios para admissão ao programa de formação inicial de professores em Ontário variam, mas exige-se, no mínimo, a conclusão do Ensino Médio (12 a série) com média $\mathrm{B}$, 
pelo menos. Em geral, na Faculdade de Educação, apenas um curso de pedagogia de Ciência e Tecnologia (isto é, metodologia de ensino) é exigido para a certificação de um programa de formação inicial de professores. Estes cursos destinam-se a apoiar a grade curricular e as instruções referentes à Ciência e Tecnologia de Ontário (CANADA, 2007).

Os cursos compreendem de 18 a quarenta horas presenciais, dependendo da ênfase institucional e do programa de formação (simultâneo versus consecutivo). É importante ressaltar que não há um número obrigatório de horas presenciais. O conteúdo do curso pode variar consideravelmente de uma universidade para outra, mas, em geral, os cursos de pedagogia em Ciências são baseados em seminários combinados com algum componente de "laboratório" e incluem alguns dos seguintes tópicos: planejamento de aulas de Ciências e avaliações; gestão de segurança e material; estratégias educacionais para o ensino de Ciências; informática; abrangência e sequência dos currículos, e como lidar com populações diversificadas de alunos.

Finalmente, a certificação de professores para o Ensino Fundamental exige um mínimo de quarenta horas de experiência prática em escolas, ainda que a maioria das universidades de Ontário espere que seus alunos cumpram um número de horas de estágio em escolas bem acima disto. Com relação aos professores para os níveis "primary/junior", não se exige nenhuma prática no ensino de Ciências; no entanto, professores para os níveis "junior/intermediate" com especialização em Ciências devem cumprir parte da experiência prática exigida em aulas de Ciências.

\section{Resultados e análises}

Os resultados são aqui apresentados e discutidos tendo em vista as semelhanças e diferenças entre os programas de formação de professores de Ciências para o Ensino Fundamental nas três jurisdições estudadas. inicial.

O Quadro 1 mostra um resumo do contexto específico dos programas de formação

Alguns resultados podem ser realçados a partir dessa análise das políticas e práticas entre os três contextos educacionais: Austrália, Brasil e Canadá.

Foi possível identificar, por meio dessa análise da formação de professores de Ciências do Ensino Fundamental, algumas semelhanças comuns aos três contextos estudados. Dentre elas, vale destacar a similaridade entre os mecanismos funcionais e estruturais que dão sustentação à formação de professores nos três países (Quadro 1).

Apesar da existência de autoridades de Educação centralizadas, como ministérios ou departamentos de Educação, que fixam alguns padrões através de legislações próprias (número de horas dos cursos, tempo de estágio), a formação de professores de Ciências para o Ensino Fundamental é decidida, em última instância, pelas instituições, Universidades dentro de suas jurisdições. São essas instituições que deliberam sobre as especificidades do currículo, dos conteúdos, das metodologias e das formas de avaliação.

Nos três contextos estudados, há uma integração entre as Ciências (os conhecimentos científicos) e a pedagogia, porém não existe um currículo único, em cada país, de formação de professores para o Ensino Fundamental. Há também uma relação entre o aprendizado de ciências e o uso das novas tecnologias. 
Garcia, P. S.; Fazio, X.; Panizzon, D.

Quadro 1. Contextos investigados em cada país - 2007/2008.

\begin{tabular}{|c|c|c|}
\hline Temas emergentes & Semelhanças & Diferenças \\
\hline $\begin{array}{l}\text { Política de Nível 1- } \\
\text { Autoridade nacional } \\
\text { em Educação }\end{array}$ & $\begin{array}{l}\text { Em cada país existem organizações que } \\
\text { pontuam expectativas mais abrangentes } \\
\text { do que específicas com relação à } \\
\text { formação de professores. }\end{array}$ & $\begin{array}{l}\text { O Brasil tem um sistema organizador } \\
\text { central (MEC). Nos outros dois países } \\
\text { esse sistema é local. AAustrália está } \\
\text { trabalhando no desenvolvimento de um } \\
\text { Currículo Nacional. }\end{array}$ \\
\hline $\begin{array}{l}\text { Política de Nível } 2 \text { - } \\
\text { Jurisdições } \\
\text { educacionais } \\
\text { localizadas }\end{array}$ & $\begin{array}{l}\text { Nos três países em questão, as } \\
\text { orientações e exigências relacionadas à } \\
\text { formação de professores são } \\
\text { especificadas, incluindo exigência de } \\
\text { horas presenciais, consistência dos } \\
\text { currículos e experiência prática. }\end{array}$ & $\begin{array}{l}\text { No Brasil essas orientações e } \\
\text { exigências são gerais para a Educação } \\
\text { Básica e para os cursos de Ciências } \\
\text { Biológicas do Ensino Médio, não } \\
\text { havendo legislação ou indicações } \\
\text { próprias para o Ensino Fundamental. } \\
\text { Em Ontário, a política estabelece } \\
\text { exigências para os cursos, mas as } \\
\text { horas presenciais não são } \\
\text { especificadas pelo OCT. }\end{array}$ \\
\hline $\begin{array}{l}\text { Política de Nível } 3- \\
\text { Universidades } \\
\text { desenvolvem } \\
\text { programas de } \\
\text { formação de } \\
\text { professores }\end{array}$ & $\begin{array}{l}\text { Em cada jurisdição, as Universidades } \\
\text { decidem, em última análise, questões } \\
\text { sobre a estrutura dos programas, } \\
\text { conteúdo a ser incluído e número de } \\
\text { horas do programa. }\end{array}$ & $\begin{array}{l}\text { Em NSW, o recentemente estabelecido } \\
\text { Institute of Teachers assegura a } \\
\text { consistência da Política de Nível } 2 \text { em } \\
\text { todas as Universidades locais. }\end{array}$ \\
\hline $\begin{array}{l}\text { Admissão flexível ao } \\
\text { programa, sem } \\
\text { nenhuma exigência } \\
\text { em relação às } \\
\text { ciências }\end{array}$ & $\begin{array}{l}\text { As exigências para professores do } \\
\text { Ensino Fundamental não incluem } \\
\text { ciências em nenhum nível, em nenhuma } \\
\text { jurisdição. }\end{array}$ & \\
\hline $\begin{array}{l}\text { Conhecimento } \\
\text { mínimo de ciências - } \\
\text { sem especialização } \\
\text { em ciências }\end{array}$ & $\begin{array}{l}\text { Os alunos completam um número } \\
\text { estabelecido de horas em ciências, bem } \\
\text { como em outras matérias. O programa } \\
\text { pode incluir palestras, oficinas e trabalhos } \\
\text { práticos. }\end{array}$ & $\begin{array}{l}\text { Em Ontário, os professores podem ter } \\
\text { uma especialização em ciências, mas } \\
\text { esta não é uma exigência. }\end{array}$ \\
\hline $\begin{array}{l}\text { Integração entre } \\
\text { ciências e pedagogia }\end{array}$ & $\begin{array}{l}\text { Em cada jurisdição há uma estreita } \\
\text { relação entre o aprendizado de ciências e } \\
\text { métodos de ensino de ciências para os } \\
\text { professores em formação, que são } \\
\text { articulados pelos princípios pedagógicos. }\end{array}$ & \\
\hline
\end{tabular}

Essa descrição dos programas de formação de professores tem, efetivamente, pelo menos, três implicações: a) ela pode favorecer futuras pesquisas, envolvendo a busca por alternativas para a organização do sistema de Ensino Fundamental; b) toda a organização da formação de professores para o Ensino Fundamental pode ser repensada; c) ela possibilita uma base de conhecimentos para fomentar a cooperação e compreensão mútua, entre os países, discutindo, de forma política e cultural, as diferenças e semelhanças na formação de professores para esse nível.

Colocadas acima as possibilidades advindas deste estudo comparativo, a questão da organização da formação de professores ganharia, no contexto brasileiro, certo destaque. Nas 
décadas passadas, a legislação da formação de professores propiciou a criação de diferentes percursos formativos para os profissionais que hoje estão atuando no Ensino Fundamental. Pode-se dizer que essa formação é a que possui o maior número de trajetórias acadêmicas. Hoje existem, nas salas de aula, professores que foram formados no esquema " $3+1$ ", outros em cursos de três anos de duração, aqueles formados exclusivamente em cursos de licenciatura curta; outros que concluíram a licenciatura curta e fizeram a complementação de seus estudos, por exemplo, em Física, Química, Biologia ou Matemática. Existem também os profissionais de outras áreas que concluíram uma complementação rápida de natureza pedagógica de acordo com a Resolução 02/97 (BRASIL, 1997), outros que já eram professores de Ciências com credenciais de licenciatura curta e se aproveitaram da mesma Resolução e plenificaram a licenciatura (GARCIA et al., 2006, 2009; MALACARNE, 2007) e, também, mais recentemente, os docentes que estão sendo formados em cursos Superiores a distância (GARCIA, 2008). Cabe lembrar ainda que, hoje, a maioria dos professores que estão se formando e ministrando aulas no Ensino Fundamental é oriunda de cursos de licenciatura plena em Biologia.

Há, no Brasil, como pode ser visto, uma grande diversidade de formação e não há uma legislação específica em relação à formação de professores de ciências para as séries finais do Ensino Fundamental, o que, de certa forma, não favorece a criação de uma identidade para esse tipo de formação, como já existe nos outros dois contextos investigados.

No caso brasileiro, essa ausência de identidade própria para a formação de professores de Ciências para o Ensino Fundamental dificulta a criação de cursos com características generalistas e com currículos adaptados ao ensino das Ciências em nível Fundamental. Ou seja, a falta de uma legislação específica para a formação desses profissionais tem também implicações sobre a qualidade da formação, afetando, consequentemente, a qualidade desse ensino.

As análises aqui realizadas possibilitarão novas reflexões daqueles que pensam e elaboram as políticas públicas relacionadas com a formação inicial de professores de Ciências para o Ensino Fundamental. O entendimento sobre outros contextos, aqui realizado, possibilita: novas ideias, alternativas, cursos, currículos, inovações e mudanças para a organização da formação de professores para esse nível de ensino.

\section{Referências}

ABELL, S. K. Science teacher education: an international perspective. Dordrecht: Kluwer, 2000.

ARGÜELO, C. A.; GIMENES, M. J. G. Licenciatura plena em ciências - Goioerê/PR. In: PROJETO pedagógico do curso de licenciatura plena em ciências/UEM. Maringá, 1991.

AUSTRALIA. Ministerial Council for Education, Early Childhood, Development and Youth Affairs. National consistency in curriculum outcomes: statements of learning and professional elaborations in science. Disponível em: <http://www.mceetya.edu.au/ mceetya/default.asp?id=11893 >. Acesso em: 21 nov. 2006. 
BRASIL. Lei de diretrizes e bases da educação nacional. Lei n. 9.394, de 20 de dezembro de 1996. Estabelece as diretrizes e bases da educação nacional. Disponível em: $<$ http://portal.mec.gov.br/arquivos/pdf/ldb.pdf>. Acesso em: 21 abr. 2005.

. Ministério da Educação e do Desporto. Secretaria da Educação Fundamental. Parâmetros Curriculares Nacionais: Ciências Naturais. Brasília: MEC/SEF, 1998a.

. Ministério da Educação e do Desporto. Secretaria da Educação Fundamental. Parâmetros Curriculares Nacionais: terceiro e quarto ciclos do Ensino Fundamental; temas transversais. Brasília: MEC/SEF, 1998b.

Lei n. 5.540, de 28 de novembro de 1968. Fixa normas de organização e funcionamento do ensino superior e sua articulação com a escola média, e dá outras providências. Brasília, 1968. Disponível em: <http://www6.senado.gov.br/legislacao/ Lista'TextoIntegral.action?id=75564>. Acesso em: 19 jul. 2003.

Câmara de Educação Básica. Parecer CEB 09/2001, aprovado em 8 de maio de 2001. Diretrizes Curriculares Nacionais para a Formação de Professores da Educação Básica, em nível superior, curso de licenciatura e de graduação plena. Documenta, Brasília, n. 476 , p. 512- 569, 2001.

. Parecer CNE/CES n. 1301/2001, de 06 de novembro de 2001. Diretrizes curriculares nacionais para os cursos de ciências biológicas. Diário Oficial [da] República Federativa do Brasil, Brasília, 07 dez. 2001. Seção 1, p. 25. Disponível em: <http:// portal.mec.gov.br/cne/arquivos/pdf/CES1301.pdf > . Acesso em: 10 mar. 2005.

. Parecer CNE/CP n. 009/2001, de 08 de maio de 2001. Diretrizes curriculares nacionais para a formação de professores da educação básica, em nível superior, curso de licenciatura, de graduação plena. Diário Oficial [da] República Federativa do Brasil, Brasília, 18 jan. 2002a. Seção 1, p. 31. Disponível em: <http://portal.mec.gov.br/cne/ arquivos/pdf/009.pdf>. Acesso em: 10 mar. 2005.

. Parecer CNE/CP n. 27/2001, de 02 de outubro de 2001. Dá nova redação ao item 3.6, alínea c, do Parecer CNE/CP 9-2001, que dispõe sobre as Diretrizes Curriculares Nacionais para a Formação de Professores da Educação Básica, em nível superior, curso de licenciatura, de graduação plena. Diário Oficial [da] República Federativa do Brasil, Brasília, 18 jan. 2002b. Seção 1, p. 31. Disponível em: <http://portal.mec.gov.br/cne/ arquivos/pdf/027.pdf>. Acesso em: 10 mar. 2005.

. Parecer CNE/CP n. 28/2001, de 02 de outubro de 2001. Dá nova redação ao Parecer CNE/CP 21/2001, que estabelece a duração e a carga horária dos cursos de Formação de Professores da Educação Básica, em nível superior, curso de licenciatura, de graduação plena. Diário Oficial [da] República Federativa do Brasil, Brasília, 18 jan. 2002c. Seção 1, p. 31. Disponível em: <http://portal.mec.gov.br/cne/arquivos/pdf/ 028.pdf $>$. Acesso em: 10 mar. 2005c. 
Formação inicial de professores de Ciências ...

Conselho Nacional de Educação. Resolução CNE/CES 7, de 11 de março de 2002. Estabelece as diretrizes curriculares para os cursos de ciências biológicas. Diário Oficial [da] República Federativa do Brasil, Brasília, 26 mar. 2002a. Seção 1, p. 13. Disponível em: < http://portal.mec.gov.br/cne/arquivos/pdf/rces07_02.pdf>. Acesso em: 10 mar. 2005.

Resolução CNE/CP 1, de 18 de fevereiro de 2002. Institui diretrizes curriculares nacionais para a formação de professores da educação básica, em nível superior, curso de licenciatura, de graduação plena. Brasília, 2002b. Disponível em: <http://portal.mec.gov.br/ cne/arquivos/pdf/CP012002.pdf >. Acesso em: 10 mar. 2005.

. Resolução CNE/CP 2, de 19 de fevereiro de 2002. Institui a carga horária dos cursos de licenciatura, de graduação plena, de formação de professores da educação básica em nível superior. Brasília, 2002c. Disponível em: <http://portal.mec.gov.br/cne/arquivos/ pdf/CP022002.pdf>. Acesso em: 10 mar. 2005.

Resolução CNE n. 2. Dispõe sobre os programas especiais de formação pedagógica de docentes para as disciplinas do currículo de ensino fundamental, do ensino médio e da educação profissional em nível médio. Brasília, 1997. Disponível em: <http:// www.diariooficial.hpg.com.br/fed_res_cne_021997.htm>. Acesso em: 21 abr. 2006.

CANADA. Council of Ministers of Education. Common framework for science learning outcomes, K-12: pan Canadian protocol for collaboration on school curriculum. Toronto: CMEC Secretariat, 1997.

. Council of Ministers of Education. Education in Canada. 2005. Disponível em: $<$ http://www.cmec.ca/international/educationcanada.en.pdf $>$. Acesso em: 5 set. 2007.

. Ministry of Education. The Ontario curriculum - science and technology: grades 1-8. Toronto, 2007. Disponível em: < http://www.edu.gov.on.ca/eng/curriculum/ elementary/scientec18currb.pdf>. Acesso em: 16 maio 2008.

Ontario College of Teachers. How programs are accredited. Toronto, 2008. Disponível em: < http://www.oct.ca/teacher_education/accreditation/ default.aspx?lang=en-CA>. Acesso em: 16 maio 2008.

CARVALHO, J. S. Programa de formação de professores. São Paulo: USP, Pró-Reitoria de Graduação, Comissão Permanente de Licenciaturas, 2004. (mimeogr.).

COBB, V. L. An international comparison of teacher education. Washington: ERIC Clearinghouse on Teaching and Teacher Education, 1999. Disponível em: <http:// eric.ed.gov/PDFS/ED436486.pdf>. Acesso em: 12 mar. 2007.

CRESWELL, J. W. Educational research: planning, conducting, and evaluating quantitative and qualitative research. New Jersey: Pearson Education, 2002.

DILLON, J.; OSBORNE, J.; FAIRBROTHER, R.; KURINA, L. A study into the professional views and needs of science teachers in primary and secondary schools in England. London: Council for Science and Technology, 2000. 
Garcia, P. S.; Fazio, X.; Panizzon, D.

DRIVER, R.; SQUIRES, A.; RUSHWORTH, P.; WOOD-ROBINSON, V. Making sense of Secondary Science: research into children's ideas. New York: Routledge, 1994.

EPP, W.; EPP, J. R. Comparing teacher education: Ontario, Canada and the TIMSS participants (England, Japan, Singapore, South Korea, United States). EQAO Research Series, Ontário, n. 5, p. 1-60, 2000. Disponível em: <http://www.eqao.com/pdf_e/01/ 01P005e.pdf>. Acesso em: 22 ago. 2007.

FAZIO, X.; BOWERS, R.; MOK, Y. Science education: a summary of research, theories, and practice - a Canadian perspective. Toronto: Thomson/Nelson, 2007.

FIGUEIREDO NETO, A. M. (Coord.). Projeto de criação do curso licenciatura em ciências da natureza. São Paulo: USP, 2003. Disponível em: < http://fma.if.usp.br/ $\sim$ coraci/USP_Leste_Licenc_20jan04.pdf >. Acesso em: 24 jan. 2007.

GARCIA, P. S. Educação superior a distância: políticas, tendências da formação de professores de ciências. In: ENCONTRO NACIONAL DE PESQUISADORES EM EDUCAÇÃO EM CIÊNCIAS, 7., 2009, Florianópolis. Anais... Florianópolis: ABRAPEC, 2009. Disponível em: < http://www.fae.ufmg.br/abrapec/viempec/7enpec/pdfs/ 1066.pdf>. Acesso em: 10 jan. 2010.

.; MALACARNE, V.; BIZZO, N. O percurso formativo, a atuação e condições de trabalho de professores de ciências de duas regiões brasileiras. Acta Scientiae, Canoas, v. 11, n. 2, p. 119-140, 2009.

.; ___ _ TOLENTINO-NETO L. C.; BIZZO, N. Two case studies about science teachers' initial preparation in Brazil. In: SYMPOSIUM OF THE INTERNATIONAL ORGANIZATION FOR SCIENCE AND TECHNOLOGY EDUCATION, 12., 2006, Penang, Malaysia. Proceedings... Penang, Malaysia: IOSTE, 2006. p. 31-36.

GOODRUM, D.; COUSINS, J.; KINNEAR, A. The reluctant primary school teacher. Research in Science Education, v. 22, n. 1, p. 163-169, 1992.

GOODRUM, D.; HACKLING, M.; RENNIE, L. The status and quality of teaching and learning of science in Australian schools: a research report. Canberra: Department of Education, Training and Youth Affairs, 2001.

HAND, B.; TREAGUST, D. F.; VANCE, K. Student perceptions of the social constructivist classroom. Science Education, New York, v. 81, n. 5, p. 561-575, 1997.

INGVARSON, L.; ELLIOT, A.; KLEINHENZ, E.; MCKENZIE, P. Teacher education accreditation: a review of national and international trends and practices. [s.l.]: Australian Council for Educational Research, 2006. (Relatório). Disponível em: <http://

research.acer.edu.au/teacher_education/1>. Acesso em: 13 jul. 2007.

KRASILCHIK, M. Prática de ensino de biologia. 4. ed. São Paulo: Edusp, 2004.

LLOYD, J.; SMITH, R.; FAY, C.; KHANG, G.; WAH, L.; SAI, C. Subject knowledge for science teaching at primary level: a comparison of pre-service teachers in England and Singapore. International Journal of Science Education, London, v. 20, n. 5, p. 521-32, 1998. 
Formação inicial de professores de Ciências ...

MAGALHÃES JR., C. A. O.; OLIVEIRA, M. P. P. Formação de professores de ciências para o ensino fundamental. In: SIMPÓSIO NACIONAL DE ENSINO DE FÍSICA, 16., 2005, Rio de Janeiro. Anais... Rio de Janeiro: SBF, 2005. Disponível em: <http:// www.sbf1.sbfisica.org.br/eventos/snef/xvi/cd/resumos/T0602-1.pdf>. Acesso em: 23 ago. 2005.

MALACARNE, V. Os professores de química, física e biologia da região oeste do Paraná: formação e atuação. 2007. 253f. Tese (Doutorado) - Faculdade de Educação, Universidade de São Paulo, São Paulo, 2007.

NEW SOUTH WALES. Board of studies. Science and technology K-6: outcomes and indicators. Sydney, 2006. Disponível em: < http://k6.boardofstudies.nsw.edu.au/files/ science-and-technology/k6_scitech_outcomes.pdf>. Acesso em: 20 jun. 2007.

NEW SOUTH WALES INSTITUTE OF TEACHERS. Professional teaching standards. Sydney, 2005. Disponível em: <http://www.nswteachers.nsw.edu.au/Main-ProfessionalTeaching-Standards.html>. Acesso em: 29 jun. 2007.

PHILLIPS, D. Learning from elsewhere in education: some perennial problems revisited with reference to British interest in Germany. Comparative Education, v. 36, n. 3, p. 297-307, 2000.

PLANO Nacional de Educação. Apresentação de Vital Didonet. 2. ed. Brasília: Plano, 2001.

REID, A. Rethinking national curriculum collaboration: towards an Australian curriculum. Canberra: Department of Education, Science and Training, 2005.

SANTOS, S.; INFANTE-MALACHIAS, M. E. Interdisciplinaridade e resolução de problemas: algumas questões para quem forma futuros professores de ciências. Educação \& Sociedade, Campinas, v. 29, n. 103, p. 557-579, 2008.

STRAUSS, A. L.; CORBIN, J. M. Basics of qualitative research: grounded theory procedures and techniques. Thousand Oaks: Sage, 1990.

UNIVERSIDADE DE SÃO PAULO. Escola de Artes, Ciências e Humanidades. Regimento dos estágios curriculares supervisionados do curso de licenciatura em ciências da natureza. São Paulo: USP, 2007. 